\title{
Assessment of the value of international genetic evaluations for yield in predicting domestic breeding values for foreign Holstein bulls
}

\author{
E. L. Nicolazzi, ${ }^{1}$ F. Forabosco, $†$ and W. F. Fikseł \\ *Istituto di Zootecnica, Facoltà di Agraria, Università Cattolica del Sacro Cuore, 29100 Piacenza, Italy \\ †Interbull Centre, Department of Animal Breeding and Genetics, Swedish University of Agricultural Sciences, Box 7023, \\ SE-75007 Uppsala, Sweden \\ ¥Department of Animal Breeding and Genetics, Swedish University of Agricultural Sciences, Box 7023, SE-75007 Uppsala, Sweden
}

\section{ABSTRACT}

International genetic evaluations are a valuable source of information for decisions about the importation of (the semen of) foreign bulls. This study analyzed data from 6 countries (Australia, Canada, Italy, France, the Netherlands, and the United States) and compared international evaluations for production traits of foreign bulls (i.e., when no national daughter information was available) to their national breeding values in August 2009, which were based only on domestic daughters' data. A total of 821 bulls with highly reliable estimated breeding values (EBV) for milk, fat, and protein yield were analyzed. No evidence of systematic over- or underestimation was found in most of the countries analyzed. Observed correlations between national and international evaluations were close to 0.9 and, for most countries, generally close to their expected values (calculated from national and international EBV reliabilities). In Italy, however, higher differences between observed and expected correlations and significant mean differences between EBV for more than one trait were observed in bulls progeny-tested in the United States and in other European countries (with differences up to $33.1 \%$ of the genetic standard deviation). These results were probably induced by a relatively recent change in the model for national evaluation. The findings in this study reflect a conservative estimate of the real value of international evaluations, as changes in methodologies in either the national or the international evaluations decreased the ability of past international evaluations to predict current national evaluations. Nevertheless, our results indicate that international evaluations based on foreign information for Holstein bulls were reasonably accurate predictors of the future national breeding values based only upon domestic daughters.

Key words: Holstein, production trait, international genetic evaluation

Received July 23, 2010.

Accepted January 22, 2011.

${ }^{1}$ Corresponding author: ezequielluis.nicolazzi@unicatt.it

\section{INTRODUCTION}

International EBV are expected to accurately predict the future performance of a bull's daughters in all countries participating in the international genetic evaluations. Since 1995, the method used to produce international EBV is a multiple-trait sire model called multiple across-country evaluation (MACE), created by Schaeffer (1994). The Interbull Genetic Evaluation Service (Uppsala, Sweden) provides international EBV for 6 dairy breeds and 7 major trait groups. In an August 2009 evaluation, MACE predictions for production traits in the Holstein breed were distributed to 26 participant countries. International information on foreign bulls is widely used by all countries, not only to improve national bull evaluations, but also to decide whether to import a foreign bull (or its semen). When domestic daughters' data for a foreign bull are not available in the importing country, possible sources of information are pedigree relationships and information about a bull's daughters in another (foreign) country, either as country of origin foreign evaluations or as (MACE) international evaluations.

Over the past 15 years, Interbull has implemented several changes in its international evaluation methods, to facilitate conversion of breeding values between countries. For example, a time edit for (the date of birth of) bulls was implemented to ensure that the base population is similar for all countries (Weigel and Banos, 1997; de Jong, 2003). In 2000, effective daughter contributions (EDC; Fikse and Banos, 2001) replaced the number of daughters as a weighting factor to more correctly account for the precision of national bull evaluations, which decreased bias in sire variance estimates and resulted in improved approximations of reliabilities. The procedure for estimating genetic correlations was reviewed in 2004 (Wilmink and Fikse, 2004), with changes implemented during the same year. Furthermore, other improvements are in development, such as the inclusion of a sire-dam pedigree, which is expected to greatly decrease the problems related to phantom grouping (de Jong, 2003; van der Linde et al., 
a)

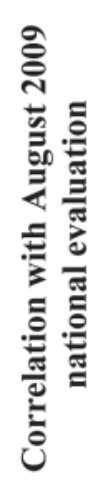

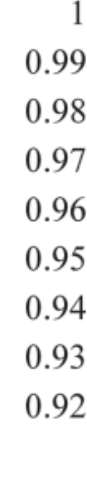

$$
96
$$
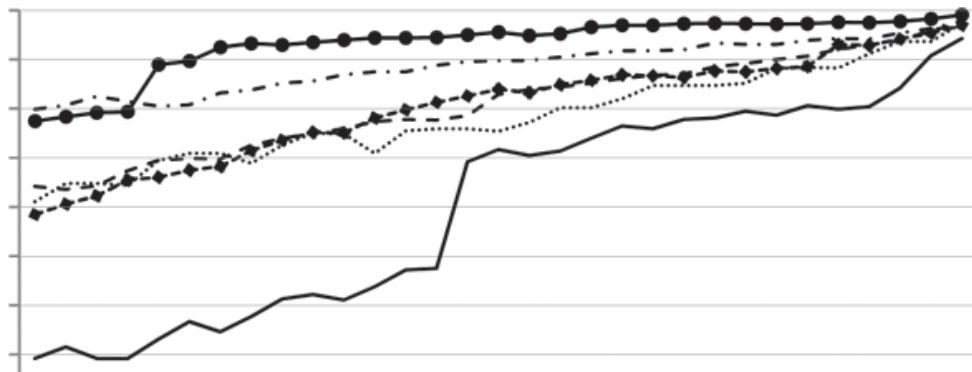

- ㄱㅇㅇ

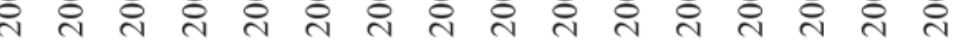

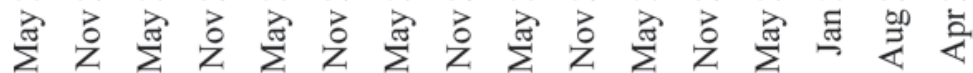

b)

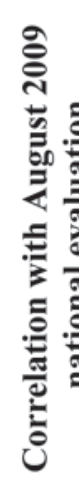

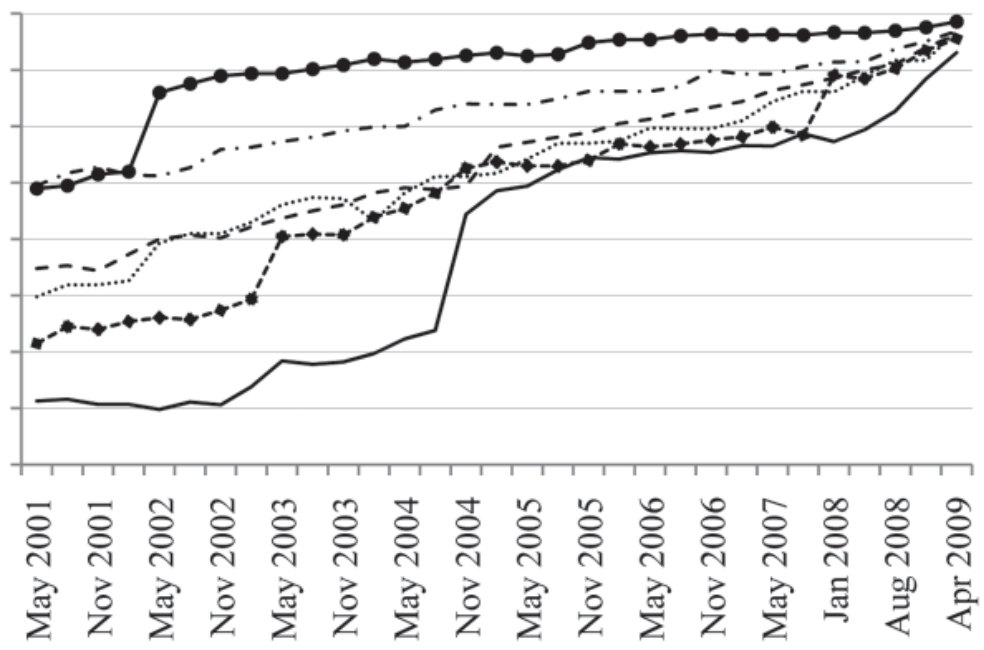

c)

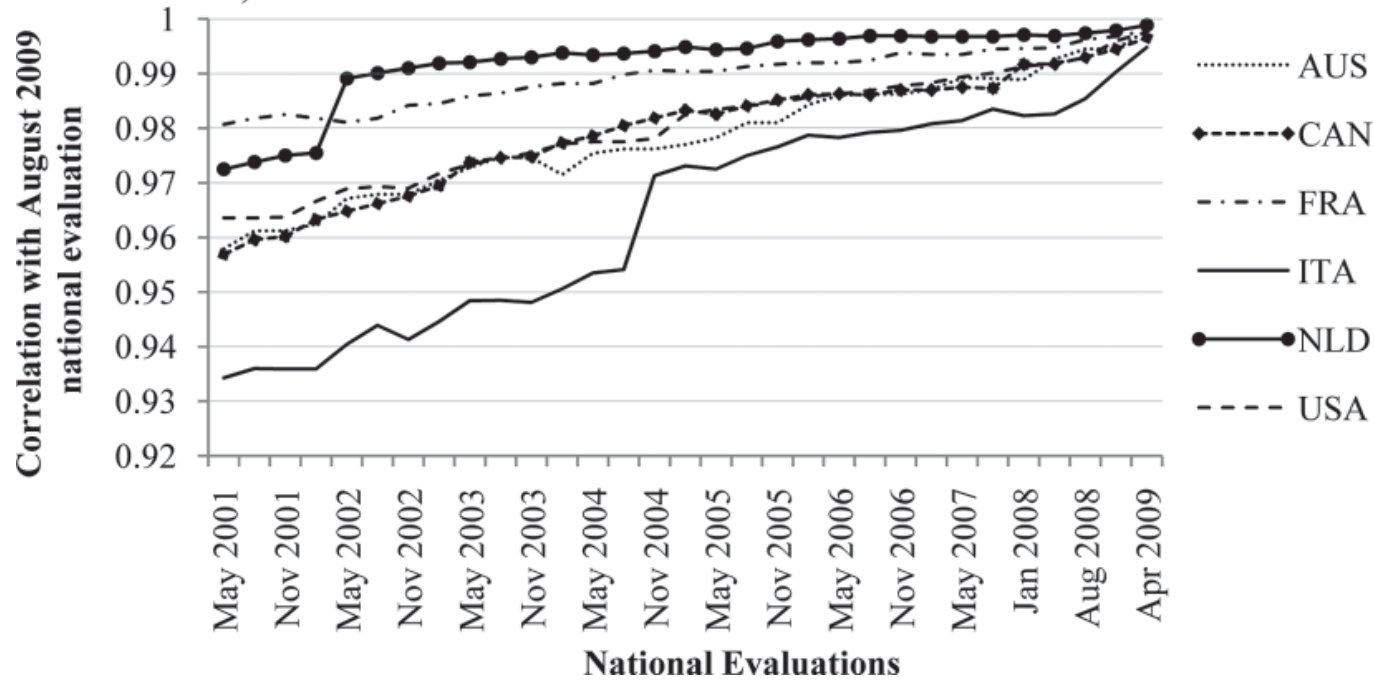

Figure 1. Within reference country correlations of national EBV in August 2009 with previous evaluations for milk (a), fat (b), and protein yield (c). Reference countries were coded as AUS (Australia), CAN (Canada), FRA (France), ITA (Italy), NLD (the Netherlands), and USA (the United States of America). 
2005; Jakobsen and Fikse, 2009), and the implementation of multiple-trait MACE (Nilforooshan et al., 2009). Interbull evaluations are under constant scrutiny, and other concerns that have been raised (Ducrocq et al. 2003; Canavesi et al., 2005) have not directly resulted in changes. Hence, monitoring of the quality of international evaluations is warranted.

Powell et al. (2000) showed that the accuracy of the United States national dairy bull evaluations (i.e., based only on national data) improved when foreign daughter information was included. Later, Powell et al. (2004) showed that parent average for production traits was not a good alternative to international EBV based on foreign daughters. Parent average underestimated bull EBV based on US daughters after semen importation. On the other hand, international evaluations were, on average, close to the US national evaluation based on US daughters. Furthermore, van der Linde and Nooijen (2004) showed that correlations in conformation traits for Holstein bulls between country of origin foreign evaluations (i.e., on the foreign country's scale) and Dutch national evaluations were up to $32 \%$ lower than those obtained comparing international and national evaluations. In addition, Brochard et al. (2006) analyzed production, udder health, and conformation traits, confirming the accuracy of international evaluations in predicting the future performance of foreign Holstein bulls in France.

Although these previous studies were of great importance in documenting the accuracy of international EBV in predicting future performance of imported bulls in different countries, the comparability of the results is somewhat limited due to differences in the approaches adopted in the analyses. In this study, we compared data from 6 countries on 3 continents using a common approach (i.e., time period, editing criteria, and statistical analysis). This facilitates a multiple-country assessment of the value of international EBV for production traits (milk, fat, and protein yield) as unbiased predictors of future performance of Holstein bulls' daughters in countries other than the test country.

\section{MATERIALS AND METHODS}

Six reference countries on 3 continents were studied: Australia (AUS), Canada (CAN), France (FRA), Italy (ITA), the Netherlands (NLD), and the United States of America (USA). Two sources of information were compared: 1) August 2009 national evaluations in each reference country (i.e., EBV based only on daughter information in the reference country, hereinafter referred to as DOM2009), and 2) previous international genetic evaluations based only on foreign daughter information (Interbull evaluations from 2001 and onwards, hereinafter referred to as INTPRED). For each reference country we retrieved a bull's last international EBV that did not include information on daughters from the reference country. Bulls missing one or both types of information were not of interest and were deleted from the analysis.

International EBV of bulls in MACE are based on pedigree relationships and progeny information. If a bull has no daughters in a particular country, MACE enables the prediction of breeding values for this bull and country by using genetic correlations among countries and daughter information from other countries. In addition, information on ancestors, currently sire and maternal grandsire, is used. In matrix notation MACE is (according to Schaeffer, 1994)

$$
\mathbf{y}_{i}=\mathbf{1} \boldsymbol{\mu}_{i}+\mathbf{Z}_{i} \mathbf{Q g}_{i}+\mathbf{Z}_{i} \mathbf{s}_{i}+\mathbf{e}_{i}
$$

where $\mathbf{y}_{i}$ is a vector of deregressed proofs (DRP) of country $i$ for a trait (e.g., milk yield); $\mathbf{1}$ is a vector of ones; $\boldsymbol{\mu}_{i}$ is the mean of the country $i ; \mathbf{Z}_{i}$ is a design matrix relating phenotypes to sires in country $i$; $\mathbf{Q}$ is a design matrix relating sires to phantom groups; $\mathbf{g}_{i}$ is a vector of phantom parent group effects; $\mathbf{s}_{i}$ is a vector of genetic effects for sires in country $i$; and $\mathbf{e}_{i}$ is a vector of random residuals. Phantom groups of unknown parents are formed by year of birth, country of origin, and path of selection (sire, maternal grandsire, maternal granddam).

To express historical evaluations on the same base and scale, linear regressions were performed of MACE EBV from August 2009 on MACE EBV from May 2001 onwards. These regressions were done separately for each country, and were based on all bulls with domestic daughters for each pair of MACE evaluations. Intercepts and slopes were used to convert all international EBV to the most recent genetic base, to allow comparisons across time. In general, intercepts were negative (i.e., because of base changes), regression coefficients were close to 1 and correlations were high (i.e., higher than $94 \%$ ), except when a change in the predictive model of a reference country was introduced (Figure 1).

To ensure comparisons between reliable EBV, animals with Interbull reliability lower than $70 \%$ or with less than 100 daughters in either the foreign or the reference country were discarded. For the same reason, only bulls with a first international evaluation before January 2004 and an uninterrupted presence in the Interbull distribution files up to August 2009 were retained.

All bulls that met the aforementioned requirements were analyzed, either together (i.e., bulls progenytested in all foreign countries included in our study) or grouped by the foreign test country. The foreign test country of a bull was defined as the country where the 
bull had the highest number of daughters in the last international genetic evaluation considered (August 2009). The assumption was that most bulls would have the highest number of daughters in the test country. Although this assumption may incorrectly assign the foreign country of some bulls, it was considered more accurate than using the country of first registration. For all reference countries, bulls progeny-tested in Italy, France, Germany, and the Netherlands were grouped together (and named EUR), because the number of bulls per country was less than 50 .

Mean and SD of differences, average reliabilities, regressions, and correlations between INTPRED and DOM2009 were calculated. Significances of differences between INTPRED and DOM2009 were tested for all 3 production traits (milk, fat, and protein yield) and in all foreign countries with a paired $t$-test. A Bonferroni correction of type I error threshold was applied to decrease false positives due to multiple testing.

All comparisons were performed on the national scale of the reference country. Mean and SD of differences between EBV were expressed in percentage of animal genetic SD of the reference country (calculated as twice the sire genetic SD obtained from Interbull, 2010). Domestic reliabilities $\left(R E L_{\text {domestic }}\right)$ were obtained as a function of EDC and heritability (Liu et al., 2004):

$$
R E L_{\text {domestic }}=\frac{E D C}{E D C+k} \times 100,
$$

where

$$
k=\frac{\sigma_{e}^{2}}{\sigma_{s}^{2}}=\frac{4-h^{2}}{h^{2}}
$$

and $\sigma_{e}^{2}$ is the residual variance, $\sigma_{s}^{2}$ is the sire variance, and $h^{2}$ is the heritability of the trait.

Because Interbull made reliabilities of international evaluations for fat and protein yield available only from March 2007 onwards, reliabilities for these traits before January 2007 were considered to be equal to milk reliabilities. As a result, reliabilities of international EBV in this study are not expected to have large variation across traits. Observed correlations were compared with their expected value, obtained following Brochard et al. (2006):

$$
\operatorname{Corr}_{\exp }=\sqrt{R E L_{\text {domestic }} \times R E L_{\text {ITB }}},
$$

where $C o r r_{\text {exp }}$ is the expected correlation, $R E L_{\text {domestic }}$ is the mean reliability of bulls in the August 2009 national evaluation of the reference country, and $R E L_{\mathrm{ITB}}$ is the (previous) international mean reliability of bulls on their latest international evaluation without daughters in the reference country.

During the time period considered (May 2001 to August 2009), models and procedures have changed for both national and international evaluations. Detailed information on these changes is available on the Interbull website (Interbull, 2010). Briefly, major changes on international evaluations included the introduction of checks on national EBV and on pedigree data received by the countries and a modification of the procedure for estimating genetic correlations.

With respect to national evaluations for production traits, Italy changed its model from a lactation model to a random regression multiple-trait, multiplelactation test-day model (TDM) in November 2004. In May 2003, Canada introduced Legendre polynomials to model the curves of their TDM. The Netherlands introduced a random regression single-trait multiplelactation TDM in November 2002. Finally, the United States introduced new adjustments to its model in February 2005 and May 2007.

\section{RESULTS AND DISCUSSION}

Eight hundred and twenty-one bulls were considered, with 518 foreign bulls present in only one reference country and the remaining 303 bulls present in more than one reference country (Table 1). A total of 1,337 cases (bulls receiving a domestic evaluation after semen import in one of the reference countries) were obtained after editing in the 6 reference countries (Table 1). The birth years of the bulls included in the analyses ranged from 1986 to 1999. The United States and Australia had the lowest number of observations (134 and 137, respectively), whereas the number of foreign bulls in Italy was the highest (336). Only 29 European bulls were found when Canada was the reference country; thus, results in this analysis must be read carefully because they might be influenced by the low number of observations. The majority of bulls had their last Interbull evaluation without daughters in the reference country before 2007 . The number of observations in the last class, generally corresponding to younger bulls, was usually lower than the other 2 classes (Table 2).

Domestic reliabilities of bulls in the August 2009 national evaluations were, on average, higher than $95 \%$ (Table 1). The reliabilities of the last Interbull evaluation without daughters in the reference country were somewhat lower (generally around 90\%), especially for Australia (79\%), due to the lower genetic correlation for production between Australia and most other countries in the Interbull evaluations (Interbull, 2010). 
Table 1. Number of bulls in the reference countries and mean (international and domestic) reliabilities for milk yield ${ }^{1}$

\begin{tabular}{|c|c|c|c|c|c|}
\hline \multirow{2}{*}{$\begin{array}{l}\text { Reference } \\
\text { country }\end{array}$} & \multirow[b]{2}{*}{ Item $^{2}$} & \multicolumn{4}{|c|}{ Foreign country ${ }^{3}$} \\
\hline & & ALL & CAN & USA & EUR \\
\hline \multirow[t]{3}{*}{$\overline{\text { Australia }}$} & Bulls (n) & 137 & & 54 & $83^{4}$ \\
\hline & Reliability int. & 79.3 & & 79.5 & 79.2 \\
\hline & Reliability dom. & 95.9 & & 95.5 & 96.1 \\
\hline \multirow[t]{3}{*}{ Canada } & Bulls (n) & 180 & & 151 & $29^{5}$ \\
\hline & Reliability int. & 90.6 & & 90.3 & 92.4 \\
\hline & Reliability dom. & 97.8 & & 97.9 & 97.4 \\
\hline \multirow[t]{3}{*}{ France } & Bulls (n) & 288 & 61 & 155 & $72^{6}$ \\
\hline & Reliability int. & 90.4 & 90.9 & 90.1 & 90.5 \\
\hline & Reliability dom. & 97.9 & 98.4 & 97.7 & 98.1 \\
\hline \multirow[t]{3}{*}{ Italy } & Bulls (n) & 336 & 52 & 199 & $85^{7}$ \\
\hline & Reliability int. & 88.1 & 88.9 & 89.1 & 85.2 \\
\hline & Reliability dom. & 97.3 & 96.9 & 97.7 & 96.5 \\
\hline \multirow[t]{3}{*}{ The Netherlands } & Bulls (n) & 262 & & 161 & $101^{8}$ \\
\hline & Reliability int. & 89.1 & & 89.4 & 88.7 \\
\hline & Reliability dom. & 97.4 & & 97.3 & 97.7 \\
\hline \multirow[t]{3}{*}{ United States } & Bulls (n) & 134 & 57 & & $77^{9}$ \\
\hline & Reliability int. & 86.7 & 87.6 & & 86.0 \\
\hline & Reliability dom. & 95.2 & 95.7 & & 94.9 \\
\hline
\end{tabular}

${ }^{1}$ Mean reliabilities in fat and protein yield do not differ more than $1.5 \%$ from those obtained in milk, and thus, are omitted for clarity.

${ }^{2}$ Reliability int. = mean of previous international reliability; reliability dom. $=$ mean of August 2009 domestic reliability.

${ }^{3} \mathrm{ALL}=$ all countries in this study, analyzed together; CAN = Canada; USA = the United States of America; EUR $=$ European countries.

${ }^{4}$ Italy (20), Germany (17), France (18), and the Netherlands (28) were grouped together.

${ }^{5}$ Italy (10), Germany (7), and the Netherlands (12) were grouped together.

${ }^{6}$ Italy (36), Germany (12), and the Netherlands (24) were grouped together.

${ }^{7}$ France (20), Germany (30), and the Netherlands (35) were grouped together.

${ }^{8}$ Italy (26), France (36), and Germany (39) were grouped together.

${ }^{9}$ Italy (22), Germany (12), France (11), and the Netherlands (32) were grouped together.

\section{Australia}

When all 137 foreign bulls were analyzed together, mean differences between INTPRED and DOM2009 were $9.4,0.1$, and $15.1 \%$ of the genetic SD for milk, fat, and protein yield, respectively (Table 3 ). None of these differences was significant $(P>0.05)$. The SD of the differences in Australia were generally the highest of all of the reference countries analyzed in this study. Such variability of differences was expected based on the lower reliability of international EBV (Table 1) resulting from the lower genetic correlations between Australia and the other reference countries analyzed (Interbull, 2010). Coefficients of regression of DOM2009 on INTPRED ranged from 1.08 to 1.16 , but were not significantly different from $1(P>0.05)$. Observed correlations between INTPRED and DOM2009 were at most $1 \%$ lower than expected (Table 4 ).

When bulls were grouped by foreign test countries, mean differences between INTPRED and DOM2009 for bulls tested in the United States were 11.6, -4.8, and $7.7 \%$ of the genetic SD for milk, fat, and protein yield, respectively. For bulls tested in EUR, mean differences between EBV for the same traits were 8.0, 3.4, and $20.5 \%$ of the genetic SD. None of these differences was significant.

Coefficients of regression of DOM2009 on INTPRED ranged from 1.01 to 1.18 , and none was significantly different from 1. McClintock et al. (2003) reported a similar trend for foreign US bulls between 2000 and 2003 in a combination of all 3 production traits (Australian Selection Index). Observed correlations between INTPRED and DOM2009 for bulls tested in the United States were as expected for milk yield and 1\% higher than expected for fat (Table 4). However, for protein yield, the observed correlation (0.84) was somewhat lower than expected (0.87). This difference could be traced to 3 closely related bulls (2 half-sib bulls and a third bull with the same maternal grandsire as one of the half-sibs) with more than 2 SD of difference between national and international EBV. On the other hand, observed correlations for bulls progeny-tested in EUR were almost as expected for milk and protein yield. However, the observed correlation for fat yield was $5 \%$ lower than its expected value. Again, a thorough analysis revealed 2 bulls with more than $2 \mathrm{SD}$ of 
Table 2. Number of bulls in the reference countries by classes of latest international genetic evaluation without domestic daughters

\begin{tabular}{|c|c|c|c|c|c|}
\hline \multirow{2}{*}{$\begin{array}{l}\text { Reference } \\
\text { country }\end{array}$} & \multirow{2}{*}{$\begin{array}{l}\text { Latest } \\
\text { international } \\
\text { evaluation }^{1}\end{array}$} & \multicolumn{4}{|c|}{ Foreign country $^{2}$} \\
\hline & & ALL & $\mathrm{CAN}$ & USA & EUR \\
\hline \multirow[t]{3}{*}{ Australia } & [2001:2003] & 68 & & 32 & $36^{3}$ \\
\hline & {$[2004: 2006]$} & 45 & & 15 & $30^{3}$ \\
\hline & [2007:2009] & 24 & & 7 & $17^{3}$ \\
\hline \multirow[t]{3}{*}{ Canada } & [2001:2003] & 61 & & 56 & $5^{3}$ \\
\hline & [2004:2006] & 72 & & 62 & $10^{3}$ \\
\hline & $2007: 2009]$ & 47 & & 33 & $14^{3}$ \\
\hline \multirow[t]{3}{*}{ France } & [2001:2003] & 169 & 34 & 91 & $44^{4}$ \\
\hline & $2004: 2006]$ & 76 & 19 & 43 & $14^{4}$ \\
\hline & [2007:2009] & 43 & 8 & 21 & $14^{4}$ \\
\hline \multirow[t]{3}{*}{ Italy } & [2001:2003] & 130 & 12 & 82 & $36^{5}$ \\
\hline & [2004:2006] & 149 & 25 & 89 & $35^{5}$ \\
\hline & [2007:2009] & 57 & 15 & 28 & $14^{5}$ \\
\hline \multirow{3}{*}{ The Netherlands } & [2001:2003] & 159 & & 115 & $44^{6}$ \\
\hline & {$[2004: 2006]$} & 52 & & 38 & $14^{6}$ \\
\hline & [2007:2009] & 22 & & 8 & \\
\hline \multirow[t]{3}{*}{ United States } & [2001:2003] & 63 & 32 & & $31^{3}$ \\
\hline & [2004:2006] & 54 & 20 & & $34^{3}$ \\
\hline & [2007:2009] & 17 & 5 & & $12^{3}$ \\
\hline
\end{tabular}

${ }^{1}[2001: 2003]$ = latest international evaluations without domestic daughter information from May 2001 to November 2003; [2004:2006] = latest international evaluations without domestic daughter information from February 2004 to November 2006; [2007:2009] = latest international evaluations without domestic daughter information from February 2007 to April 2009.

${ }^{2} \mathrm{ALL}=$ all countries in this study, analyzed together; CAN = Canada; USA = the United States of America; $\mathrm{EUR}=$ European countries.

${ }^{3}$ Italy, Germany, France, and the Netherlands were grouped together.

${ }^{4}$ Italy, Germany, and the Netherlands were grouped together.

${ }^{5}$ France, Germany, and the Netherlands were grouped together.

${ }^{6}$ Italy, France, and Germany were grouped together.

difference between national and international EBV. A common feature among these 5 extreme bulls mentioned above was the information collected about daughters and sons in several countries that contributed to the latest international EBV, as well as a low reliability of international EBV (on average, $74 \%$ ).

\section{Canada}

Canada's set of analyzed foreign countries was the same as that of Australia (Table 1). However, large differences were observed in either the total number of bulls (180) or the number of bulls specific to each foreign country. In fact, the number of bulls progeny-tested in the United States was almost 3-fold (151), and the number tested in EUR (29) was roughly one-third. No bulls progeny-tested in France were retained after editing. When bulls were analyzed together, mean differences between INTPRED and DOM2009 were 8.1, -9.7, and $11.0 \%$ of the genetic SD for milk, fat, and protein yield, respectively (Table 3$)$. A significant difference $(P<$ 0.05 ) was found for fat yield, which could be attributed to bulls progeny-tested in the United States. Coefficients of regression of DOM2009 on INTPRED ranged from 1.04 to 1.11 and were not significantly different from unity. Observed correlations between INTPRED and DOM2009 were always lower than the expected correlations $(-4,-1$, and $-3 \%$ for milk, fat, and protein yield, respectively). For bulls progeny-tested in the United States, mean differences between INTPRED and DOM2009 for milk and protein yield were similar to those for US bulls in Australia, but the SD of differences were 8 and $5 \%$ lower for both traits, respectively (Table 3). A significant mean difference between EBV of $-11.8 \%$ of the genetic SD was observed for fat yield $(P<0.05)$. This was somewhat unexpected, especially considering the large number of common bulls in both countries' pedigrees. Eleven bulls had differences in EBV from INTPRED and DOM2009 that were greater than $2 \mathrm{SD}$ in at least 1 of the 3 production traits. The latest international evaluation without daughters in Canada for all these bulls was before November 2005 . Many major changes in methodologies and models were introduced in both countries before that evaluation. For example, in May 2003, Canada changed from Wilmink to Legendre polynomials to model the curves used in their TDM, and in February 2005, the United States introduced a package of adjustments to its national model (VanRaden and Tooker, 2010). The effect of these changes on the results obtained in this study 
Table 3. Mean and standard deviations of differences (expressed as percent of genetic standard deviation) for milk, fat, and protein yield traits, between national EBV based only on domestic daughters (August 2009) and latest international EBV without domestic daughters in each reference country ${ }^{1}$

\begin{tabular}{|c|c|c|c|c|c|c|c|c|c|}
\hline \multirow[b]{3}{*}{$\begin{array}{l}\text { Reference } \\
\text { country }\end{array}$} & \multirow[b]{3}{*}{ Trait } & \multicolumn{8}{|c|}{ Foreign country $^{2}$} \\
\hline & & \multicolumn{2}{|c|}{ ALL } & \multicolumn{2}{|c|}{ CAN } & \multicolumn{2}{|c|}{ USA } & \multicolumn{2}{|c|}{ EUR } \\
\hline & & Mean & $\mathrm{SD}$ & Mean & SD & Mean & $\mathrm{SD}$ & Mean & $\mathrm{SD}$ \\
\hline \multirow[t]{3}{*}{ Australia } & Milk yield & 9.4 & 47.9 & & & 11.6 & 49.3 & 8.0 & $47.2^{3}$ \\
\hline & Fat yield & 0.1 & 47.3 & & & -4.8 & 40.5 & 3.5 & $51.5^{3}$ \\
\hline & Protein yield & 15.1 & 52.4 & & & 7.7 & 49.7 & 20.5 & $54.1^{3}$ \\
\hline \multirow[t]{3}{*}{ France } & Milk yield & -0.2 & 37.5 & 1.9 & 32.6 & -0.1 & 37.8 & -2.2 & $41.0^{4}$ \\
\hline & Fat yield & -5.6 & 34.4 & -0.2 & 25.2 & -9.1 & 36.6 & -2.3 & $35.8^{4}$ \\
\hline & Protein yield & 6.8 & 40.4 & 12.3 & 36.2 & 4.2 & 41.3 & 7.6 & $41.7^{4}$ \\
\hline \multirow[t]{3}{*}{ Italy } & Milk yield & $18.4^{* * *}$ & 46.7 & 2.6 & 44.2 & $21.0^{* * *}$ & 45.8 & $22.0 * *$ & $48.6^{5}$ \\
\hline & Fat yield & 7.1 & 45.7 & -2.3 & 45.3 & 4.6 & 44.4 & $18.4^{*}$ & $47.2^{5}$ \\
\hline & Protein yield & $22.0^{* * *}$ & 50.3 & 1.6 & 48.0 & $22.6^{* * *}$ & 48.1 & $33.1^{* * *}$ & $53.2^{5}$ \\
\hline & Protein yield & $6.7^{*}$ & 23.2 & 0.9 & 21.6 & & & $11.1^{* *}$ & $23.5^{3}$ \\
\hline
\end{tabular}

${ }^{1}$ Mean differences between EBV were calculated as: $100 \times$ (latest national EBV - international EBV)/ $\sigma_{\mathrm{g}}$, where $\sigma_{\mathrm{g}}$ is the animal genetic standard deviation. Significance thresholds were corrected for multiple testing.

${ }^{2} \mathrm{ALL}=$ all countries in this study, analyzed together; CAN = Canada; USA $=$ the United States of America; EUR $=$ European countries.

${ }^{3}$ Italy, Germany, France, and the Netherlands were grouped together.

${ }^{4}$ Italy, Germany, and the Netherlands were grouped together.

${ }^{5}$ France, Germany, and the Netherlands were grouped together.

${ }^{6}$ Italy, France, and Germany were grouped together.

${ }^{*} P<0.05$; ${ }^{*} P<0.01$; *** $P<0.001$.

was tested, retaining only bulls included in the latest international evaluation without Canadian daughters after November 2005 (50 bulls). When considering only these bulls, mean differences between INTPRED and DOM2009 were greatly decreased $(-2.01,-4.67$, and $0.53 \%$ of the genetic SD for milk, fat, and protein yield, respectively) and nonsignificant, and the SD of differences between EBV was almost halved (18.90, 18.25, and $21.67 \%$ of the genetic SD). Thus, the significant difference for protein yield between INTPRED and DOM2009 was more likely caused by changes in the models and the procedures rather than by an actual bias of international EBV.

None of the coefficients of regression of DOM2009 on INTPRED were significantly different from unity, with values ranging from 0.99 for milk yield for bulls tested in EUR to 1.11 for fat yield for bulls tested in the USA. Observed correlations for bulls tested in EUR were close to their expected values $(-1,-1$, and $0 \%$ differences between observed and expected correlations for milk, fat, and protein yield, respectively). Observed correlations for bulls tested in the USA were 0.89, 0.92, and 0.91 for milk, fat, and protein yield, respectively, and somewhat lower than expected (Table 4). Considering only US bulls included in the last international evaluation without domestic daughters after November 2005, observed correlations matched their expected value for milk yield, and were $1 \%$ higher than expected for fat and protein yield.

\section{France}

Foreign bulls progeny-tested in CAN, the USA, and EUR were considered (Table 1). When all bulls were analyzed together, mean differences between INTPRED and DOM2009 were generally small and nonsignificant for all traits. A significantly different from one coefficient of regression of DOM2009 on INTPRED of 0.92 was found for fat yield, whereas the 2 nonsignificant regression coefficients ranged from 0.90 to 0.91 . Observed correlations between INTPRED and DOM2009 were always lower than expected, but only with a maximum of $2 \%$ difference (for milk and fat yield).

The highest mean differences between EBV (expressed in percent of the genetic standard deviation) for bulls grouped by foreign test country were found for 
Table 4. Expected (Exp. $)^{1}$ and observed (Obs. $)^{2}$ correlations for milk, fat, and protein yield for each reference country

\begin{tabular}{|c|c|c|c|c|c|c|c|c|c|}
\hline \multirow{2}{*}{$\begin{array}{l}\text { Reference } \\
\text { country }\end{array}$} & \multirow[b]{2}{*}{ Trait } & \multicolumn{8}{|c|}{ Foreign country $^{3}$} \\
\hline & & Exp. & Obs. & Exp. & Obs. & Exp. & Obs. & Exp. & Obs. \\
\hline \multirow[t]{3}{*}{ Australia } & Milk yield & 0.87 & 0.88 & & & 0.87 & 0.87 & 0.87 & $0.88^{4}$ \\
\hline & Fat yield & 0.87 & 0.86 & & & 0.87 & 0.88 & 0.87 & $0.82^{4}$ \\
\hline & Protein yield & 0.87 & 0.86 & & & 0.87 & 0.84 & 0.87 & $0.86^{4}$ \\
\hline \multirow[t]{3}{*}{ France } & Milk yield & 0.94 & 0.92 & 0.95 & 0.92 & 0.94 & 0.93 & 0.94 & $0.90^{5}$ \\
\hline & Fat yield & 0.94 & 0.92 & 0.95 & 0.95 & 0.94 & 0.92 & 0.94 & $0.90^{5}$ \\
\hline & Protein yield & 0.94 & 0.93 & 0.94 & 0.91 & 0.94 & 0.92 & 0.94 & $0.92^{5}$ \\
\hline \multirow[t]{3}{*}{ Italy } & Milk yield & 0.93 & 0.88 & 0.93 & 0.87 & 0.93 & 0.87 & 0.91 & $0.88^{6}$ \\
\hline & Fat yield & 0.93 & 0.87 & 0.93 & 0.87 & 0.93 & 0.88 & 0.91 & $0.83^{6}$ \\
\hline & Protein yield & 0.92 & 0.85 & 0.93 & 0.82 & 0.93 & 0.86 & 0.90 & $0.83^{6}$ \\
\hline United States & Protein yield & 0.91 & 0.91 & 0.92 & 0.86 & & & 0.90 & $0.91^{4}$ \\
\hline
\end{tabular}

${ }^{1}$ Expected correlations were obtained from the square root of the product of mean international and domestic reliabilities.

${ }^{2}$ Observed (Pearson) correlations.

${ }^{3} \mathrm{ALL}=$ all countries in this study, analyzed together; CAN = Canada; USA $=$ the United States of America; EUR = European countries.

${ }^{4}$ Bulls tested in Italy, Germany, France, and the Netherlands were grouped together.

${ }^{5}$ Bulls tested in Italy, Germany, and the Netherlands were grouped together.

${ }^{6}$ Bulls tested in France, Germany, and the Netherlands were grouped together.

${ }^{7}$ Bulls tested in Italy, France, and Germany were grouped together.

protein yield for bulls progeny-tested in CAN and in EUR, and for fat yield for foreign US bulls $(12.3,7.6$, and $-9.1 \%$, respectively). However, none of the mean differences was significant.

Coefficients of regression of DOM2009 on INTPRED ranged from 0.83 for fat yield for bulls tested in EUR (the only regression coefficient found to be significantly deviating from unity, $P<0.05)$ to 1.01 for fat yield for bulls progeny-tested in CAN. Observed correlations between INTPRED and DOM2009 ranged from 0.90 for protein yield for bulls tested in EUR to 0.95 for fat yield for bulls tested in CAN (Table 4). These results were reasonably similar to those reported by Brochard et al. (2006). In fact, Brochard et al. (2006) obtained slightly higher observed correlations between national and international EBV for bulls tested in CAN and the USA, although lower observed correlations were reported for bulls tested in EUR. However, differences in the methods implemented in both studies make a comparison of results difficult. In particular, in Brochard et al. (2006) the grouping of bulls was by country of first registration, whereas in the present study it was the country with the highest number of daughters in August 2009. Another reason is the different time period and editing criteria adopted in this paper, resulting in a different number of bulls analyzed. Brochard et al. (2006) considered a shorter time period (from 2000 to 2005), whereas our study includes 4 more years of international evaluations. Finally, the editing criteria in Brochard et al. (2006) were less strict for international evaluations (only a reliability higher than $70 \%$ was required to include bulls in the analysis) and more stringent for national evaluations (at least 150 daughters, corresponding to a reliability higher than $90 \%$ ) than the criteria adopted in this study.

\section{Italy}

Bulls progeny-tested in CAN, the USA, and EUR were analyzed. Large mean differences between INTPRED and DOM2009 were found for all traits (18.42, 7.06 , and $22.0 \%$ of the genetic SD for milk, fat, and protein yield, respectively) when all bulls were analyzed together (Table 4). The differences for milk and protein yield were highly significant $(P<0.001)$. Regression coefficients of DOM2009 on INTPRED ranged from 1.01 to 1.04 and were not significantly different from 1 for all traits. Observed correlations between INTPRED and DOM2009 were between 5\% (milk yield) and $7 \%$ (protein yield) lower than expected. When bulls 
progeny-tested in the different foreign countries were analyzed separately, lower mean differences between INTPRED and DOM2009 were found for all traits for bulls tested in CAN, although the SD of differences was similar to those obtained for the other foreign countries (Table 3). Lower mean differences between EBV of ITA and CAN were expected, considering that since November 2004, both countries have used a similar TDM model for production traits (Canavesi et al., 2004). Highly significant $(P<0.001)$ mean differences between EBV were found for milk and protein yield for US progeny-tested bulls and for protein yield for bulls tested in France, Germany, and the Netherlands. Moreover, for foreign bulls tested in EUR, significant mean differences in EBV were also found for milk $(P<$ $0.01)$ and fat yield $(P<0.05)$. Surprisingly, the SD of differences between INTPRED and DOM2009 for bulls tested in the USA and in EUR were similar to, and in 2 cases, higher than, those obtained with Australia as a reference country.

Coefficients of regression of DOM2009 on INTPRED for the 3 foreign countries were not significantly different from 1 and ranged from 0.95 for protein yield in EUR to 1.06 for milk yield in the USA, indicating that in the countries and traits with significant mean differences, a systematic underestimation of international predictions occurs. Observed correlations between INTPRED and DOM2009 were lower than expected in all foreign countries and traits (Table 4). Differences between observed and expected correlations ranged from $-11 \%$ (protein yield for bulls tested in CAN) to $-3 \%$ (milk yield for bulls tested in EUR).

The effect of the relatively recent introduction of TDM on national EBV correlations in all traits was more profound in Italy compared with the introduction of TDM in other countries such as Canada or the Netherlands (Figure 1). With respect to international evaluations, the introduction of TDM affected genetic correlations between Italy and the other countries. In addition, in November 2004, Interbull introduced a new method of estimating genetic correlations that caused further effect on genetic correlations between countries (Interbull, 2010). Considering that these changes in methodologies may have a large effect on results, further analyses were performed. Foreign bulls in the USA and in EUR were divided into 2 subgroups, corresponding to the 2 periods with different predictive models in Italy. The first subgroup (LAC) included bulls with the latest international genetic evaluation without Italian daughters from May 2002 to May 2004 (i.e., corresponding to the time period during which Italy used a lactation model). The remaining bulls formed a second subgroup (ATDM), corresponding to the time period after the introduction of TDM in Italy.
International evaluations for bulls in the LAC subgroup were compared with August 2004 Italian EBV, and those for bulls in the ATDM subgroup were compared with August 2009 national EBV. Observed correlations for bulls tested in EUR decreased from 0.93, 0.93, and 0.91 for milk, fat, and protein yield, respectively, in the LAC subgroup, to $0.81,0.80$, and 0.79 , respectively, for the same traits in the ATDM subgroup. Surprisingly, for bulls progeny-tested in the USA, lower differences in observed correlations between the 2 subgroups were observed. Observed correlations for all traits in the LAC subgroup were 0.87 . They were only 1 and $2 \%$ lower for milk and protein yield, respectively, and $3 \%$ higher for fat yield than the ATDM subgroup. Note that bulls progeny-tested in CAN were omitted because the number of observations in both subgroups was low. Higher variability of correlations between national and international evaluations across time within TDM evaluations had already been reported by van Kaam et al. (2008). In recent years, many efforts have been made to deal with the problem of TDM indices' stability in Italy (Canavesi et al., 2008a,b, 2009). These improvements, however, are too recent to evaluate in the present study.

\section{The Netherlands}

Bulls progeny-tested in the USA and EUR were considered in the analysis (Table 1). When all bulls were analyzed together, mean differences between INTPRED and DOM2009 were always small and negative $(-3.7$, -3.5 , and $-2.5 \%$ of the genetic SD for milk, fat, and protein yield, respectively). None of these differences was significant. Regression coefficients of DOM2009 on INTPRED ranged from 0.94 (milk yield) to 0.96 (fat and protein yield) and were nonsignificantly different from 1. Observed correlations between INTPRED and DOM2009 were always lower than expected $(-4 \%$, $-3 \%$, and $-2 \%$ for the aforementioned traits, respectively).

Mean differences between INTPRED and DOM2009 for bulls grouped by single foreign test country were negative for all traits, with at most $-3.8 \%$ of the genetic SD difference for milk yield (for bulls progeny-tested in the USA). None of the mean differences between EBV was significant (Table 3). van der Linde and Nooijen (2004) reported similar mean differences between EBV with Canada, Germany, and France as foreign countries, with a smaller number of bulls included in the analysis.

Coefficients of regression of DOM2009 on INTPRED were lower than 1 in all traits, with values ranging from 0.93 to 0.98 , except for protein yield for bulls progenytested in EUR (1.03). Again, none of these regression 
coefficients deviated significantly from unity. Observed correlations between INTPRED and DOM2009 for US progeny-tested bulls were about 0.9 (2 to $3 \%$ lower than expected). Lower observed correlations were found for bulls tested in EUR, with values ranging from 0.87 for milk and fat yield to 0.90 for protein yield (Table 4). In this case, 10 bulls were found with differences greater than $2 \mathrm{SD}$ in at least 1 of the production traits. Eight of these extreme bulls had been progeny-tested in Italy and France, 2 countries with different predictive models from the Netherlands. Other than this, no clear pattern for the extreme bulls was found: international reliabilities were only $2 \%$ lower than the average of all other bulls; national reliabilities were, on average, with the non-outlier bulls; the time of the last international evaluation without Dutch daughters ranged from November 2002 to January 2007; birth years of the bulls ranged from 1994 to 1998; and except for 3 half-sibs, no clear pedigree structure was found.

\section{The United States}

Foreign bulls progeny-tested in CAN and EUR were considered in the analysis (Table 1). When considering all bulls together, mean differences between INTPRED and DOM2009 were low, positive, and not significant for milk and fat yield (4.9 and $3.1 \%$ of the genetic $\mathrm{SD}$, respectively). A significant mean difference between EBV of $6.7 \%$ of the genetic SD was obtained for protein yield. Regression coefficients of DOM2009 on INTPRED ranged from 1.01 to 1.05 for the 3 production traits, but were not significantly different from 1 . Observed and expected correlations between INTPRED and DOM2009 were generally similar. Observed correlations were 2 and $1 \%$ lower than expected for milk and fat yield, respectively, whereas they matched for protein yield. As for the previous reference countries, specific analyses for each bull's foreign test country were performed. For CAN progeny-tested bulls, low mean differences between INTPRED and DOM2009 were observed $(1.6,0$, and $0.9 \%$ of genetic SD for milk, fat, and protein, respectively). Larger mean differences between EBV were observed for bulls tested in EUR, with a significant $(P<0.01)$ mean difference of $11.1 \%$ of the genetic SD for protein yield. The SD of differences for all traits and both foreign countries were the lowest of all of the reference countries analyzed (values ranged from 20.1 to $23.5 \%$ of the genetic SD).

Coefficients of regression of DOM2009 on INTPRED ranged from 0.90 for protein yield for bulls tested in CAN to 1.05 for fat yield for bulls progeny-tested in EUR. None of these values deviated significantly from unity. Observed correlations between INTPRED and
DOM2009 for bulls tested in CAN $(0.88,0.88$, and 0.86 for milk, fat, and protein yield, respectively) were similar to those reported by Powell et al. (2004), although both studies differ not only in the period of time considered (from 1995 to 2004 in the Powell et al., 2004 study) but also in the number of bulls included in the analysis. Powell et al. (2004) retained bulls with higher national and international EBV reliabilities (80\%) than those used in this study, but did not set a threshold on the number of daughters for both national and international evaluations. As a result, the editing adopted in the present study was more stringent, as indicated by the higher average reliabilities $(+1.7$ and +3.6 average reliability in national and international evaluations, respectively). Similar to the results obtained for the USA's foreign bulls from Canada, the 6 CAN bulls progeny-tested in the USA with differences greater than 2 SD between national and international EBV for at least 1 of the 3 production traits, had their latest international evaluation without US domestic daughters before November 2005. Furthermore, 4 of these extreme bulls had a common pedigree with the extreme bulls found when Canada was the reference country (only sires and maternal grandsires were checked).

Observed correlations between INTPRED and DOM2009 for bulls tested in EUR were almost as expected, with a maximum of $\pm 1 \%$ difference between observed and expected correlations for all traits. For these bulls, comparisons of realized correlations with those obtained by Powell et al. (2004) were not possible.

\section{Final Considerations}

Mean differences between INTPRED and DOM2009 based on 2 independent (national and foreign) groups of daughters were generally small and, in most cases, not significant. Almost all regression coefficients of DOM2009 on INTPRED did not deviate significantly from unity. In fact, only 1 regression coefficient was significant (fat yield for bulls progeny-tested in EUR when considering France as a reference country). Observed correlations between INTPRED and DOM2009 were generally similar to their expected values.

Although possibly influenced by the low number of bulls included in the analyses, these results indicate that, except for Italy, no evidence of systematic problems exists in the international evaluation of production traits or specific foreign countries.

Modifications in methodologies in either the national or the international evaluations might have influenced our findings (i.e., Italy, Canada). As a consequence, this study may make a conservative estimate of the 
real value of international foreign evaluations, as these changes could actually be responsible for some of the variation found.

The expected correlations were based on reliability of domestic and international evaluations, which, in turn, were based on EDC. Both EDC and the methods to compute reliabilities are approximate methods, and the expected correlations in this study are, thus, subject to approximation errors. Approximation methods typically lead to overestimation of reliability, the degree of which depends on genetic evaluation models and data structure. This means that expected correlations in the present study probably imply an upper bound.

The choice to retain only bulls with $70 \%$ EBV reliability and at least 100 daughters in both the foreign and the reference country had a direct effect on the number of young bulls included in the analysis (Table 2 ). By requiring such highly reliable EBV, the variability of results obtained in this study was more likely to be affected by past changes in predictive models and procedures in both national and international evaluations. To verify the effect of the editing criteria, we performed all analyses using bulls with at least $60 \% \mathrm{EBV}$ reliability in the domestic evaluation as the only editing criterion. Although observed and expected correlations were somewhat lower, as expected, we confirmed that the agreement between observed and expected correlations was as good as the results in Table 4. Thus, it appeared that our observations also apply to younger bulls with lower reliabilities. In addition, all analyses were performed by weighting the information of a bull's EDC against the bulls retained after editing, but these results were very similar to those of the unweighted analyses.

The range of birth years among the bulls included was $13 \mathrm{yr}$, but relatively few young bulls were included as a consequence of our editing criteria. The amount and sources of information differ based on the age of the bull, where older bulls typically have higher reliabilities due to larger daughter group sizes and more information on other close relatives such as full/half-sib brothers. To determine whether the agreement between international and domestic evaluations depended on the age, each data set was divided in 2 halves based on year of birth (old: born before 1994; and young: born after 1995). No specific trend in regression coefficients was found for the 2 groups (data not shown). In general, lower correlations were expected and observed for the group of young bulls, corresponding to a lower reliability of their EBV.

The criterion used to assign the foreign bulls' country of origin might not have been optimal. In fact, this criterion might have wrongly assigned some bulls, especially in countries where the use of imported bulls is intensive (i.e., Italy), contributing to an increase in the variability of results.

This study analyzed performance of bulls tested in different production systems and with different national evaluation models, genetic parameters, and number of genetic links between countries. However, even if countries were selected to cover a wide variety of scenarios, these results can only be considered as a general indication for countries not involved in the current analysis.

\section{CONCLUSIONS}

Results obtained in this study show that international genetic evaluations for yield traits based on foreign daughter performance are reasonably accurate predictors of national EBV of bulls in most countries. In fact, except for Italy, no strong bias was observed and realized correlations between national and international EBV obtained were generally close to 0.90 . Italian results were most probably influenced by several circumstances that might have affected the outcome in this analysis. Nevertheless, results obtained in this study agreed well with previous studies that compared national and international evaluations.

\section{ACKNOWLEDGMENTS}

The authors acknowledge Daniel Abernethy and Gert Nieuwhof (Australian Dairy Herd Improvement Scheme, ADHIS, Melbourne), Brian Van Doormaal (Canadian Dairy Network, CDN, Guelph, ON, Canada), Sophie Mattalia (Institut National de la Recherche Agronomique, INRA, Jouy en Josas cedex, France), Fabiola Canavesi (Associazione Nazionale Allevatori Frisona Italiana, ANAFI, Cremona, Italy), Gerben de Jong (CRV, Nijmegen, the Netherlands) and Paul VanRaden (USDA, Beltsville, MD) for their comments and suggestions, and for providing the necessary information for this study. Paolo Ajmone-Marsan (Università Cattolica del Sacro Cuore, Piacenza, Italy) and João Dürr (Interbull Centre, Swedish University of Agricultural Sciences, Uppsala, Sweden) are kindly acknowledged. Helpful comments and suggestions from the 3 anonymous reviewers are also acknowledged. E. L. Nicolazzi was partly funded by an AGRISYSTEM $\mathrm{PhD}$ fellowship (ciclo XIII).

\section{REFERENCES}

Brochard, M., S. Minéry, and S. Mattalia. 2006. Accuracy of international evaluations in predicting French estimated breeding values of foreign Holstein bulls. Pages 67-71 in Proc. Interbull Annu. Mtg., Kuopio, Finland. Interbull No. 35. Interbull, Uppsala, Sweden.

Canavesi, F., S. Biffani, and F. Biscarini. 2004. Test day model for production traits and SCS for the Italian Holstein. J. Dairy Sci. 87(Suppl. 1):40 (Abstr.) 
Canavesi, F., S. Biffani, and F. Biscarini. 2006. Sire variance trends over time: Is there an answer to an old problem? Pages 122-126 in Proc. Interbull Annu. Mtg., Kuopio, Finland. Interbull No. 35. Interbull, Uppsala, Sweden.

Canavesi, F., S. Biffani, G. Bramante, and R. Finocchiaro. 2009. Improving the stability of test day model evaluation for production traits in the Italian Holstein. Ital. J. Anim. Sci. 8(Suppl. 2):39 41.

Canavesi, F., S. Biffani, E.L. Nicolazzi, and R. Finocchiaro. 2008a. Improving stability of test day model bull proofs. J. Dairy Sci. 91(E-Suppl. 1):544.

Canavesi, F., G. B. Jansen, E. L. Nicolazzi, S. Biffani, and R. Finocchiaro. 2008b. Impact of data editing on fat and protein content on stability of test day model evaluation. Pages $32-35$ in Proc. Interbull Annu. Mtg., Niagara Falls, USA. Interbull No. 38. Interbull, Uppsala, Sweden.

Ducrocq, V., I. Delaunay, D. Boichard, and S. Mattalia. 2003. A general approach for international genetic evaluations robust to inconsistencies of genetic trends in national evaluations. Pages 101-111 in Proc. of the Interbull Technical Workshop, Beltsville, MD. Interbull No. 30. Interbull, Uppsala, Sweden.

de Jong, G. 2003. MACE-Options for improvement. Pages 112-116 in Proc. of the Interbull Technical Workshop, Beltsville, MD. Interbull No. 30. Interbull, Uppsala, Sweden.

Fikse, W. F., and G. Banos. 2001. Weighting factors of sire daughter information in international genetic evaluations. J. Dairy Sci. 84:1759-1767.

Interbull. 2010. Genetic evaluations: Production. Accessed March 24, 2010. http://www-interbull.slu.se/eval/framesida-prod.htm.

Jakobsen, J., and F. Fikse. 2009. Sire-dam pedigree in MACE-Results from a full-scale pilot study. Pages 91-98 in Proc. Interbull International Workshop, Uppsala, Sweden. Interbull No. 39. Interbull, Uppsala, Sweden.

Liu, Z., F. Reinhardt, A. Bunger, and R. Reents. 2004. Derivation and calculation of approximate reliabilities and daughter yield-deviations of a random regression test-day model for genetic evaluation of dairy cattle. J. Dairy Sci. 87:1896-1907.
McClintock, S., K. Beard, and R. Poole. 2003. Interbull proofs are a reasonably unbiased prediction of future performance in Australia for imported bulls. Pages 169-170 in Proc. Interbull Annu. Mtg., Rome, Italy. Interbull No. 31. Interbull, Uppsala, Sweden.

Nilforooshan, M. A., J. Jakobsen, W. F. Fikse, B. Berglund, and H. Jorjani. 2009. MT-MACE for female fertility and milk yield. Pages 68-71 in Proc. Interbull Annu. Mtg., Barcelona, Spain. Interbull No. 40. Interbull, Uppsala, Sweden.

Powell, R. L., H. D. Norman, and G. Banos. 2000. Improving prediction of national evaluations by use of data from other countries. J. Dairy Sci. 83:368.

Powell, R. L., A. H. Sanders, and H. D. Norman. 2004. Accuracy of foreign dairy bull evaluations in predicting United States evaluations for yield. J. Dairy Sci. 87:2621-2626.

Schaeffer, L. R. 1994. Multiple-country comparison of dairy sires. J. Dairy Sci. 77:2671-2678.

van der Linde, R., A. P. W. de Roos, A. G. F. Harbers, and G. de Jong. 2005. MACE with sire-mgs and animal pedigree. Pages 3-7 in Proc. Interbull Annu. Mtg., Uppsala, Sweden. Interbull No. 33. Interbull, Uppsala, Sweden.

van der Linde, R., and M. Nooijen. 2004. De waarde van Interbull. Pages 12-14 in Veeteelt, Januari 1/2. Interbull, Uppsala, Sweden.

van Kaam, J. B. C. H. M., R. Finocchiaro, F. Canavesi, and S. Biffani. 2008. Assessment of predictive ability of MACE for production traits of Italian and foreign bulls. Pages 158-162 in Proc. Interbull Annu. Mtg. Niagara Falls, NY. Interbull No. 38. Interbull, Uppsala, Sweden.

VanRaden, P. M., and M. E. Tooker. 2010. Genetic base changes for February 2005. AIPL, USDA research report. Accessed March 24, 2010. http://www.aipl.arsusda.gov/reference/base2005.htm.

Weigel, K. A., and G. Banos. 1997. Effect of time period of data used in international dairy sire evaluations. J. Dairy Sci. 80:3425-3430.

Wilmink, J. B. M., and W. F. Fikse. 2004. Report from workshop in Uppsala. Pages 33-36 in Proc. Interbull Annu. Mtg., Sousse, Tunisia. Interbull No. 32. Interbull, Uppsala, Sweden. 